\title{
Rapid Dopamine Signaling in the Nucleus Accumbens during Contingent and Noncontingent Cocaine Administration
}

\author{
Garret D Stuber', Mitchell F Roitman², Paul EM Phillips ${ }^{3,4}$, Regina M Carelli ${ }^{1,2}$ and R Mark Wightman*,1,5 \\ 'Curriculum in Neurobiology, University of North Carolina at Chapel Hill, Chapel Hill, NC, USA; ${ }^{2}$ Department of Psychology, University of North \\ Carolina at Chapel Hill, Chapel Hill, NC, USA; ${ }^{3}$ Department of Psychiatry and Behavioral Sciences, University of Washington, Seattle, WA, USA; \\ ${ }^{4}$ Department of Pharmacology, University of Washington, Seattle, WA, USA; ${ }^{5}$ Department of Chemistry and Neuroscience Center, University of \\ North Carolina at Chapel Hill, Chapel Hill, NC, USA
}

\begin{abstract}
Cocaine acts as a reinforcer through its pharmacological effects on brain monoaminergic systems, which, through repeated pairings with environmental stimuli, lead to the development of conditioned effects of the drug. Both the pharmacological and conditioned aspects of cocaine are implicated in several facets of acquisition and maintenance of addiction, including drug craving. Here, we compare the effects of contingent (response dependent) and noncontingent (response independent) cocaine on rapid dopaminergic signaling in the core of the nucleus accumbens. Dopamine was monitored using fast-scan cyclic voltammetry. Noncontingent cocaine administered to both naïve and animals with a history of self-administration resulted in a profound increase in the frequency of transient dopamine release events that are not time-locked to any specific environmental stimuli. Pharmacological effects were detectable approximately $40 \mathrm{~s}$ after cocaine administration. In contrast, when animals where allowed to self-administer cocaine on an FR-I schedule, dopamine transients $(69 \pm 12 \mathrm{nM})$ were consistently observed time-locked to each reinforced response (peaking approximately $1.5 \mathrm{~s}$ after response completion). Importantly, no pharmacological effect of cocaine was observed within the $10 \mathrm{~s}$ following noncontingent cocaine administration, indicating that dopamine signals time-locked to the reinforced response are a result of the pairing of the operant behavior, the drug-associated cues, and cocaine. These data demonstrate that this pharmacological action of cocaine occurs for an extended period following either contingent or noncontingent administration, but is distinct from those dopamine transients that are time-locked to each lever-press in self-administering animals.

Neuropsychopharmacology (2005) 30, 853-863, advance online publication, 17 November 2004; doi:1 0.1038/sj.npp. I 3006I9
\end{abstract}

Keywords: dopamine; accumbens; cocaine; reinforcement; drug abuse; voltammetry

\section{INTRODUCTION}

Dopaminergic neurotransmission in the mesolimbic system is associated with reward seeking (Everitt and Robbins, 2000; Salamone and Correa, 2002; Phillips et al, 2003b), prediction (Schultz, 1998; Waelti et al, 2001), and reinforcement (Wise, 1982, 2004). Owing to this, dopamine has been implicated in the neurobiological actions of many drugs of abuse, particularly those of cocaine (Di Chiara and Imperato, 1988; Di Chiara et al, 2004; Koob et al, 2004; Wise, 2004). Through its pharmacological actions, cocaine directly affects dopaminergic terminals by inhibiting dopamine uptake (Jones et al, 1995). Cocaine use leads to

\footnotetext{
*Correspondence: Professor RM Wightman, Department of Chemistry and Neuroscience Center, The University of North Carolina, CB\# 3290, Venable Hall, Chapel Hill, NC 27599-3290, USA, Tel: + I 919 962 |472, Fax: + I 919962 2388, E-mail: rmw@unc.edu

Received 27 August 2004; revised II October 2004; accepted 13 October 2004

Online publication: 18 October 2004 at http://www.acnp.org/citations/ NPPI01804040389/default.pdf
}

the development of conditioned effects through the pairing of the drug to environmental cues (Stewart, 1992; Volkow et al, 2003; Ciccocioppo et al, 2004; See et al, 2003), and these play a key role in the onset and maintenance of addiction (Gawin, 1991; O'Brien et al, 1992; Dackis and O'Brien, 2001). Microdialysis studies have revealed increases in extracellular nucleus accumbens dopamine during cocaine self-administration (Pettit and Justice, 1989, 1991; Wise et al, 1995; Bradberry, 2000). However, it has proved more difficult for microdialysis investigations of dopamine to resolve the pharmacological effects of cocaine from the conditioned effects because the sampling timescale is multiple minutes (Bradberry, 2000). Despite this, increases in dopamine on a minute timescale have been demonstrated by microdialysis in response to discriminative (Weiss et al, 2000) and conditioned (Ito et al, 2000) stimuli associated with cocaine self-administration.

Electrophysiological studies during operant behavior have shown that neuronal activity increases on a subsecond timescale during events associated with cocaine selfadministration (Chang et al, 1994; Uzwiak et al, 1997; 
Carelli et al, 2000; Carelli, 2004). Thus, it is important to know whether dopamine can change on this timescale as well. Dopaminergic terminals form synapses on the neck of spines and dendrites of the projection neurons in the nucleus accumbens, and are in close proximity to glutametergic synapses originating from neurons in the hippocampus, basolateral amygdala, and prefrontal cortex (Totterdell and Smith, 1989; Sesack and Pickel, 1990; Johnson et al, 1994). Thus, dopamine is in a prominent position to modulate these inputs (O'Donnell et al, 1999; Nicola et al, 2000) and exert control over the activity of microcircuits within the nucleus accumbens that ultimately control behavior (Pennartz et al, 1994). Recently, we demonstrated that fast-scan cyclic voltammetry can be used to monitor dopamine changes during cocaine self-administration on a subsecond timescale (Phillips et al, 2003b). This technique is particularly well suited for measurement of transient dopamine release events (Rebec et al, 1997; Phillips et al, 2003a), defined here as signals greater than $\sim 15 \mathrm{nM}$ and lasting less than $3 \mathrm{~s}$ (ie dopamine transients) that may arise from phasic firing of dopamine neurons (Venton et al, 2003a). Transient dopamine changes in the nucleus accumbens were found to occur during the $\pm 10 \mathrm{~s}$ interval surrounding a rat's lever press to self-administer cocaine. The dopamine transients before the lever press appeared to promote cocaine seeking, whereas those that followed the lever press were closely time-locked to it and the accompanying cues.

In this work, we have furthered our investigation of subsecond dopamine changes that accompany cocaine administration. We first investigated the actions of noncontingent cocaine on both drug-naïve animals and animals with a history of cocaine self-administration. The high time resolution of the voltammetric technique allowed resolution of cocaine-induced dopamine transients under these conditions, which were not associated with any discernible behavioral responses. In rats trained to lever-press for cocaine, its self-administration caused similar transients due to the pharmacological effects of cocaine in addition to dopamine transients that were time-locked to each lever press. Thus, transients related to the pharmacological effects of cocaine accompany those that arise from the conditioned effects during self-administration.

\section{MATERIALS AND METHODS}

\section{Animals}

Male Sprague-Dawley rats $(n=18$; Harlan, Raleigh, NC; 280-300 g), individually housed on a 12:12 light cycle (lights on at $0700 \mathrm{~h}$ ), were surgically implanted with an intravenous catheter under ketamine hydrochloride $(100 \mathrm{mg} / \mathrm{kg}$ i.m.) and xylazine hydrochloride $(20 \mathrm{mg} / \mathrm{kg}$ i.m.) anesthesia, as described previously (Caine and Koob, 1994; Carelli and Deadwyler, 1996). Following recovery, rats had ad libitum access to food, while water intake was restricted to $30 \mathrm{ml} /$ day (above $85 \%$ of their presurgery weight) to maintain body weight and to remain consistent with our previous studies. All procedures were in accordance with the University of North Carolina Animal Care and Use Committee.

\section{Cocaine Self-Administration Training}

Following 1 week recovery from catheter surgery, some rats $(n=8)$ were trained to self-administer cocaine during $2 \mathrm{~h}$ daily sessions. Rats were placed in a sound-attenuated operant chamber (Med Associates, St Albans, VT) and a cue light located $6.5 \mathrm{~cm}$ above the lever was illuminated to signal drug availability. Depression of the lever (FR1 schedule) resulted in simultaneous termination of the cuelight $(20 \mathrm{~s})$, onset of a tone-houselight stimulus $(65 \mathrm{~dB}, 2900 \mathrm{~Hz} ; 20 \mathrm{~s})$ and intravenous cocaine infusion $(0.33 \mathrm{mg}$ in sterile heparinized saline over $6 \mathrm{~s}$ ). During the $20 \mathrm{~s}$ post response period responding on the lever was recorded, but had no programmed consequences. Stable self-administration behavior $(<10 \%$ variability in press number during a consecutive 3 -day period) was typically achieved by $10-15$ training sessions, and at this time rats were surgically prepared for voltammetric recording.

\section{Voltammetry Surgery}

Rats were anesthetized with ketamine hydrochloride $(100 \mathrm{mg} / \mathrm{kg}$ i.m. $)$ and xylazine hydrochloride $(20 \mathrm{mg} / \mathrm{kg}$ i.m.) and placed in a stereotaxic frame. A guide cannula (Bioanalytical Systems, West Lafayette, IL) was positioned with its tip above the right nucleus accumbens core $(+1.3 \mathrm{~mm} \mathrm{AP},+1.3 \mathrm{~mm} \mathrm{ML},-2.5 \mathrm{~mm} \mathrm{DV}$ relative to bregma), an $\mathrm{Ag} / \mathrm{AgCl}$ reference electrode was placed in the contralateral forebrain, and these were secured to the cranium with machine screws and cranioplastic cement. When cured, a detachable micromanipulator containing a carbon-fiber electrode (50-75 $\mu \mathrm{m}$ length cylinders, T-650; Amoco, Greenville, SC) was inserted into the guide cannula and the electrode was lowered into the nucleus accumbens core. A bipolar stimulating electrode was lowered into the ventral tegmental area (VTA; $-5.2 \mathrm{~mm} \mathrm{AP},+1.0 \mathrm{~mm} \mathrm{ML}$, and $-7.7 \mathrm{~mm} \mathrm{DV}$ ) until electrically evoked (60 biphasic pulses, $60 \mathrm{~Hz}, 120 \mu \mathrm{A}, 2 \mathrm{~ms} /$ phase) dopamine release was detected at the carbon-fiber electrode. The stimulating electrode was then cemented, and the micromanipulator was removed and replaced with a stylet. Following surgery, rats were allowed to recover for at least 3 days.

\section{Voltammetry Recording Sessions}

On the experimental day, a new carbon-fiber electrode was lowered into the nucleus accumbens core. Voltammetric recordings were made every $100 \mathrm{~ms}$ by applying a triangular waveform $(-0.6$ to $+1.4 \mathrm{~V}, 400 \mathrm{~V} / \mathrm{s})$. Data were digitized in a PC using software written in LabVIEW (National Instruments, Austin, TX). Dopamine release was optimized within the nucleus accumbens core by adjusting the vertical position of the working electrode $(0.1 \mathrm{~mm}$ increments). Experiments were begun when a site that had a signal-tonoise ratio of electrically evoked (24 biphasic pulses, $60 \mathrm{~Hz}$, $120 \mu \mathrm{A}, 2 \mathrm{~ms} /$ phase) dopamine release of at least 30 was found. After the session, dopamine release was again electrically evoked to insure that carbon-fiber electrode was still in close proximity to a dopamine release site, and then the carbon-fiber electrode was removed and calibrated with dopamine $(1 \mu \mathrm{M})$ in a flow-injection analysis system (Phillips et al, 2003a). 


\section{Noncontingent Cocaine Infusions}

The response to noncontingent cocaine delivery was examined in rats that had been trained to self-administer cocaine $(n=5)$ and a separate group of cocaine-naïve animals $(n=5)$. Rats in the noncontingent group received identical treatment and surgery as rats self-administering cocaine. Rats were acclimated to the recording chamber (a different chamber to self-administration training) for $1 \mathrm{~h}$, and then given four, 6 -s infusions of saline ( $5 \mathrm{~min}$ apart), followed by four, 6 -s infusions of cocaine $(0.33 \mathrm{mg} /$ infusion; the dose used in self-administration), while voltammetric recordings were made.

\section{Cocaine Self-Administration}

Self-administering rats were re-trained following voltammetry surgery for an additional 2-3 days to re-establish their behavior. On the experimental day, voltammetric data were collected and behavioral events were logged (Med Associates) on separate PCs that were digitally linked to allow synchronization of neurochemical and behavioral measurements during a cocaine self-administration session.

\section{Signal Identification and Correction}

Chemical identification of signals was carried out by examining background-subtracted cyclic voltammograms (Phillips and Wightman, 2003). The subtraction process yields changes in concentration that cannot be used to establish absolute levels (Phillips et al, 2003a). To isolate dopamine transients, a 'sliding background' subtraction was used. In this approach, each cyclic voltammogram in a 2min file was subtracted from the average of the five cyclic voltammograms collected $1.0-0.5 \mathrm{~s}$ earlier. Each background-subtracted cyclic voltammogram was compared by linear regression to an in vivo dopamine template (average background-subtracted cyclic voltammogram recorded during electrically evoked dopamine release). Only voltammograms with an $r^{2} \geqslant 0.75$ were considered dopamine; the remainder of the signal was considered noise.

While the cyclic voltammograms for norepinephrine and dopamine are virtually identical, in vitro analysis shows that $r^{2}>0.75$ distinguishes dopamine from other interferences (Heien et al, 2003) such as ascorbic acid, DOPAC, ionic changes in the extracellular space (Venton et al, 2003b), and noise. Norepinephrine is unlikely to be a significant contributor to the signal because its content in the nucleus accumbens is only $2 \%$ of that of dopamine (Garris et al, 1993), and immunohistochemical labeling of dopamine- $\beta$ hydroxylase is not detectable in this region (Baldo et al, 2003).

Examination of the cyclic voltammograms revealed that in addition to dopamine other chemical changes, such as changes in $\mathrm{pH}$, were frequently detected. To remove their contribution, current measured at a potential that is not sensitive to dopamine $(\sim 200 \mathrm{mV} v s \mathrm{Ag} / \mathrm{AgCl})$ was subtracted from the current at the peak oxidation potential for dopamine $(\sim 650 \mathrm{mV} v s \mathrm{Ag} / \mathrm{AgCl})$. The current was then converted into concentration by calibrating the electrodes in vitro with $1 \mu \mathrm{M}$ dopamine.
Characterization of the amplitude and duration of fluctuations in dopamine in self-administering animals within $\pm 10 \mathrm{~s}$ of a lever press employed Mini-analysis software (Synaptosoft, Decatur, GA). Typical noise levels were equivalent to $6 \mathrm{nM}$ dopamine. Only peaks with amplitudes that remained three times greater than the noise for at least $1.5 \mathrm{~s}$ were evaluated. Consecutive peaks were distinguished if they occurred after the prior event had decayed by at least $40 \%$.

\section{Histology}

Following completion of experiments, rats were deeply anesthetized (ketamine hydrochloride, $150 \mathrm{mg} / \mathrm{kg}$; xylazine hydrochloride, $20 \mathrm{mg} / \mathrm{kg}$ ) and a stainless steel electrode (50- $\mu \mathrm{m}$ tip radius) was lowered to the recording site with the same micromanipulator, and an electrolytic lesion was made $(50 \mu \mathrm{A}, 10 \mathrm{~s})$. Rats were then transcardially perfused with physiological saline, followed by $4 \%$ paraformaldehyde. Brains were stored in $4 \%$ paraformaldehyde for at least 3 days, frozen, and sectioned with a cryostat $(50 \mu \mathrm{m})$. Brain sections were mounted on slides, stained with thionin, and coverslipped. Serial sections were examined under a light microscrope and all recording sites were verified to be located in the core region of the nucleus accumbens with the aid of a brain atlas (Paxinos and Watson, 1997).

\section{RESULTS}

\section{Electrically and Behaviorally Evoked Dopamine Release}

During insertion of the carbon fiber, electrical stimulation of the dopamine-containing cell bodies was used to evoke dopamine release. Prior studies have shown that electrical stimulation of the VTA and/or medial forebrain bundle causes a transient increase in extracellular dopamine in the nucleus accumbens (Kuhr et al, 1986; Garris et al, 1997), followed by a secondary basic change in local $\mathrm{pH}$ that correlates with increased local blood flow (Venton et al, $2003 \mathrm{~b}$ ). Both of these signals are readily detected electrochemically using fast-scan cyclic voltammetry with carbonfiber microelectrodes. Figure 1a (top) shows electrically evoked dopamine release both before (dotted trace) and after (solid line) correction for the ionic changes that resemble $\mathrm{pH}$. In this example, dopamine release was evoked using parameters that are analogous to burst firing of dopaminergic neurons (eight pulses, $30 \mathrm{~Hz}, 120 \mu \mathrm{A}$ ). Cyclic voltammograms taken immediately after the electrical stimulation confirms that the signal is dopamine, while those taken a few seconds later are consistent with the voltammograms for a basic $\mathrm{pH}$ change (Figure 1a bottom). The cyclic voltammogram obtained at the end of the stimulation was used as the template for dopamine identification during behaviorally evoked events in vivo (Phillips and Wightman, 2003).

Behaviorally evoked dopamine transients had several similar characteristics. Figure $1 \mathrm{~b}$ shows an example of phasic dopamine time-locked to the operant response for cocaine. The cyclic voltammogram was identical to that obtained during stimulated release. The time course, corrected for nondopaminergic components, showed an increase slightly before the lever press and a larger increase 
occurring immediately after the lever press (solid line). Without the correction for ionic changes (dotted trace), the increase appeared to be followed by a longer lasting

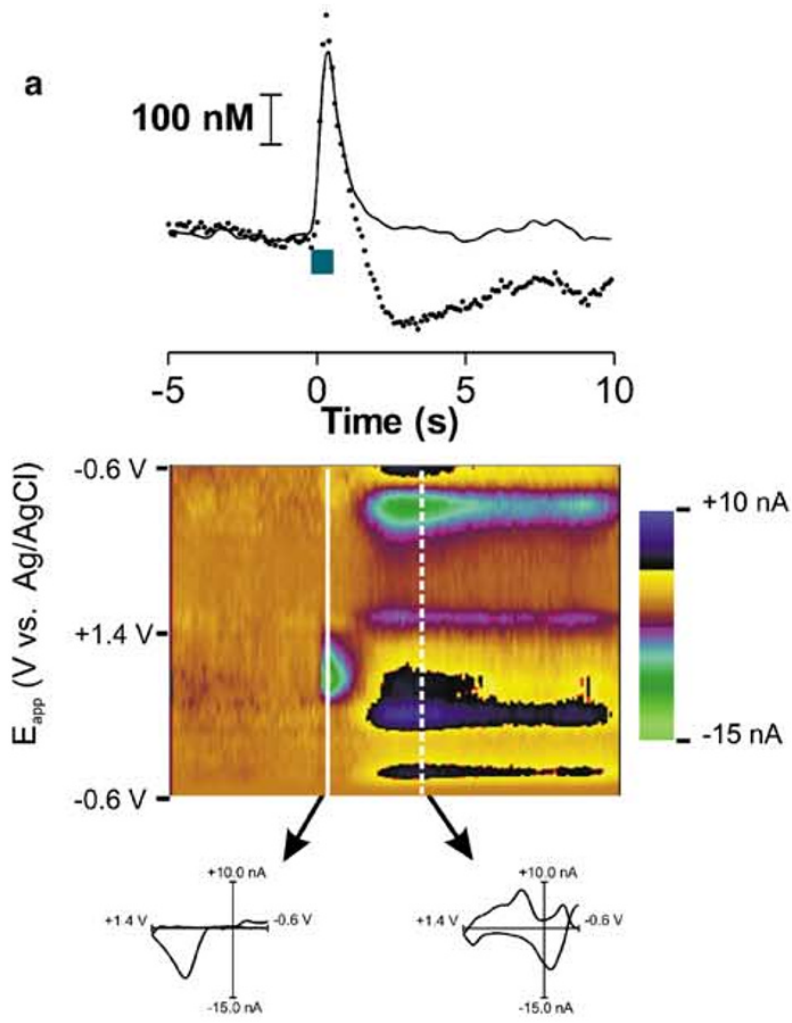

b
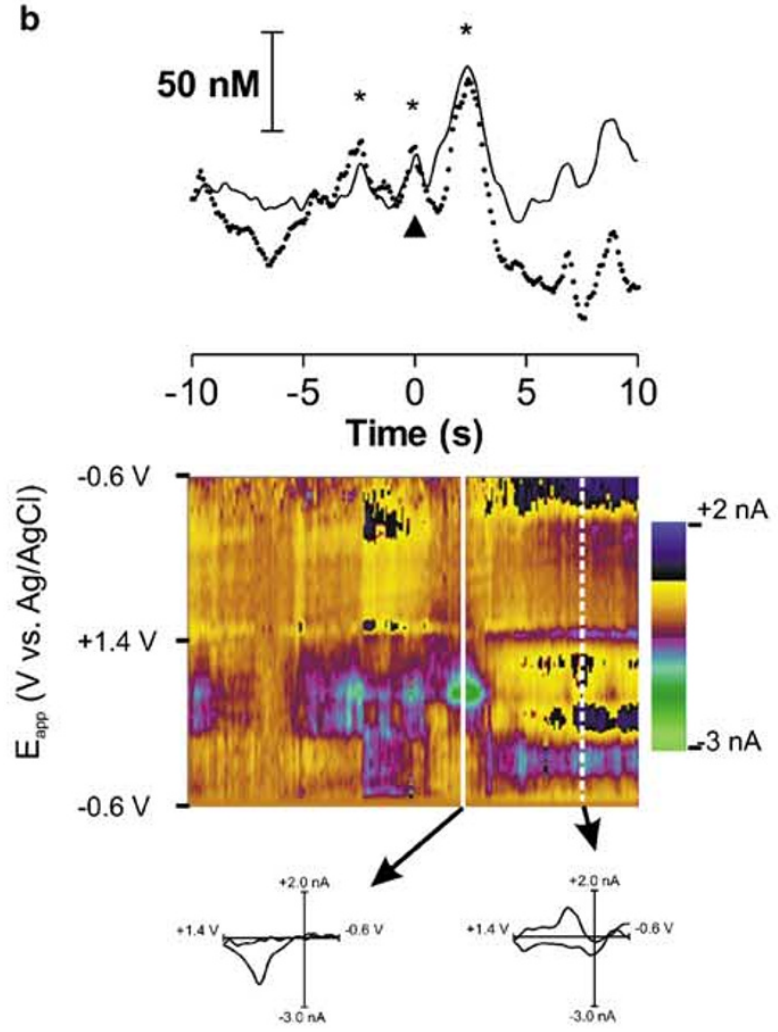

decrease in current after the lever-press response that has cyclic voltammograms, which are also consistent with a basic $\mathrm{pH}$ change. In the remainder of the text, all traces have been $\mathrm{pH}$ corrected.

\section{Pharmacological Effects of Cocaine on Dopaminergic Terminals in the Nucleus Accumbens}

Cocaine is a competitive inhibitor of the dopamine transporter, and, as such, it prolongs the lifetime of dopamine in the extracellular fluid. As shown previously, (Wu et al, 2001) the prolonged lifetime in the nucleus accumbens can be directly observed with fast-scan cyclic voltammetry following evoked release caused by electrical stimulation of dopamine-containing cell bodies in anesthetized animals.

In self-administering animals, similar effects on evoked release were seen. At the beginning of self-administration sessions, the position of the carbon-fiber electrode within the nucleus accumbens was optimized to a site where robust dopamine release was evoked with electrical stimulation of the VTA. During the stimulation, the current arising from dopamine oxidation, corrected for interference from other substances, increased (an example is shown in Figure 2a). Dopamine rapidly returned to baseline when the stimulation terminated. At the end of the 2-h self-administration sessions, consisting of $19 \pm 1.1$ lever presses in eight animals, the stimulation was repeated. In all cases, dopamine release was observed, verifying that the recording site still supported dopamine release (an example is shown in Figure 2b). Typically, evoked dopamine release was greater after the session, and it returned to baseline in $5.3 \pm 0.39 \mathrm{~s}$, significantly slower than the $2.6 \pm 0.16 \mathrm{~s}$ observed before the session ( $p \leqslant 0.01$; Student's $t$-test).

Cocaine administration also caused the frequency of naturally occurring dopamine transients to increase. Recent improvements in the sensitivity of the voltammetric approach (Heien et al, 2003) allow resolution of periodic fluctuations in dopamine in the nucleus accumbens extracellular fluid (Robinson et al, 2002). The example

Figure I Signal identification and correction of voltammetric data recorded in the NAc. (a) (Top): dopamine release (solid line) measured by cyclic voltammetry during electrical stimulation of the VTA $(8 p, 30 \mathrm{~Hz}$, $120 \mu \mathrm{A}$; delivered at $t=0 \mathrm{~s}$ ) in a single trial. The signal before correction for ionic changes (dashed line) is also shown at the potential at which dopamine is oxidized. (a) Colored panel: the set of all backgroundsubtracted cyclic voltammograms recorded over the $15 \mathrm{~s}$ interval. The ordinate is the applied potential $\left(E_{\mathrm{app}}\right)$ during each voltammogram, the abscissa is the time at which it was recorded, and the current changes are encoded in color. Dopamine can be seen during stimulation by the features at $0.650 \mathrm{~V}$ (oxidation peak encoded as green) and at $-0.20 \mathrm{~V}$ at the end of the voltage scan. Individual cyclic voltammograms from this set are shown for the end of the stimulation and at the time indicated by the white dashed line. The former is identical to that for authentic dopamine, while the latter is consistent with an ionic change at the electrode. (b) (Top): dopamine release (solid line) during a single lever-press response for cocaine (lever press at $t=0 \mathrm{~s}$ ). The signal before correction for ionic changes (dashed line) is also shown. The color plot reveals dopamine changes before and after the lever press, as well as ionic changes after the lever press. Dopamine transients are denoted in the trace by asterisks. The cyclic voltammogram I s after the lever press is consistent with dopamine $\left(r^{2}=0.89\right)$ and the cyclic voltammogram at $8 \mathrm{~s}$ after the lever press is consistent with an ionic change. 


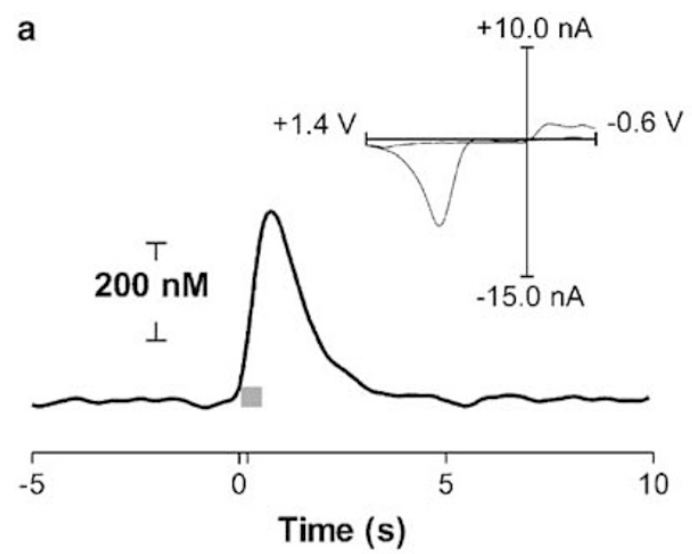

C

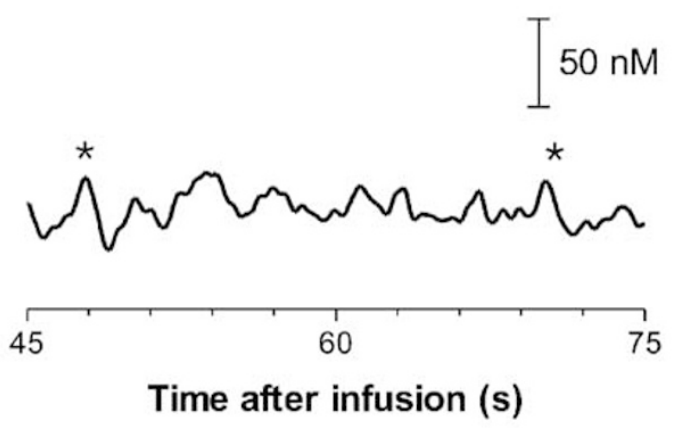

e

noncontingent saline

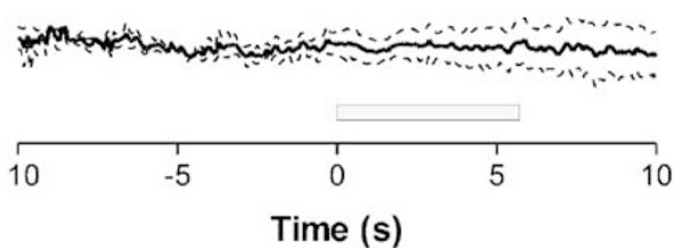

b
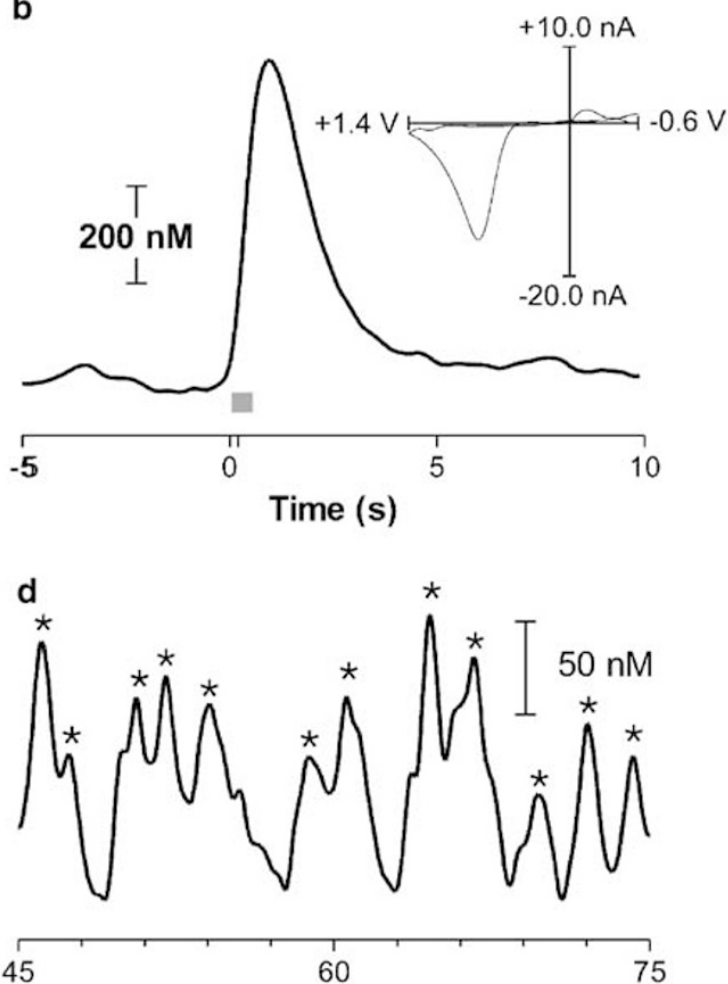

Time after infusion (s)

f

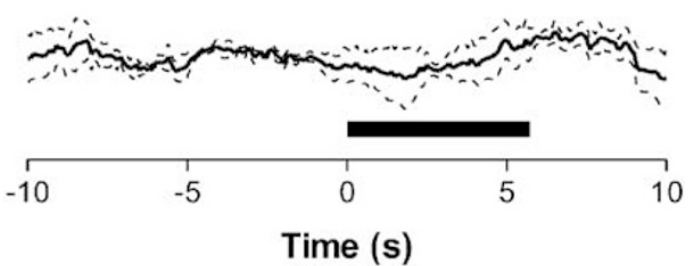

Figure 2 Pharmacological responses to cocaine measured with in vivo voltammetry. (a) Example of electrically evoked $(24$ pulses, $60 \mathrm{~Hz}, 120 \mu \mathrm{A}$; gray box) dopamine release before a cocaine self-administration session. The dopamine signal was extracted from the voltammetric recordings. The cyclic voltammogram shown (insert) was recorded at the maximum response and confirms that dopamine is the substance detected. (b) Electrically stimulated release in the same animal after a cocaine self-administration session. The cyclic voltammogram shown (inset) was recorded at the maximum and has a high correlation with authentic dopamine. (c) A 30 s trace from an individual animal after a noncontingent i.v. infusion of saline. (d) Trace from the same animal after a noncontingent i.v. infusion of cocaine. In (c, d) peaks with an asterisk were due to dopamine since their cyclic voltammograms correlated with electrically evoked dopamine with an $r^{2}>0.75$. (e) Average trace \pm SEM (dotted lines) ( $n=5$ animals) for dopamine changes during saline infusion. ( $f$ ) Average trace ( $n=5$ animals) for dopamine changes during noncontingent cocaine infusion. Black bars show the infusion duration.

shown in Figure 2c, recorded in a cocaine-naïve rat after a saline infusion, illustrates these naturally occurring transients. The asterisks denote maxima whose voltammograms matched those of dopamine with an $r^{2} \geqslant 0.75$. However, $45 \mathrm{~s}$ after noncontingent infusion of $0.33 \mathrm{mg}$ cocaine to this animal, the dopamine transients increased in frequency and amplitude (Figure 2d). The changes were neither immediate nor synchronized with the infusion: averaged traces collected for $10 \mathrm{~s}$ immediately following either saline or cocaine infusion do not show dopamine changes (Figure 2e and f; averaged across five animals).

When examined on a slower timescale, the frequency of dopamine transients from recordings in five animals that were naïve to cocaine correlated closely $(r=0.8)$ to the computed local concentration of cocaine (Pan et al, 1991; Figure 3a). While the frequency of dopamine transients was unchanged by saline infusions, in the first minute after cocaine infusion, the frequency increased and then declined as the local cocaine concentration declined. The baseline also increased in the first minute following cocaine infusion, and it reached $20 \%$ of its final value $38.1 \pm 17.0 \mathrm{~s}$ after initiation of cocaine infusion. The frequency of dopamine transients increased with subsequent cocaine infusions as well, although the relative increase was not as large as the relative change in local cocaine concentration. Overall, the frequency of dopamine transients during saline infusions 

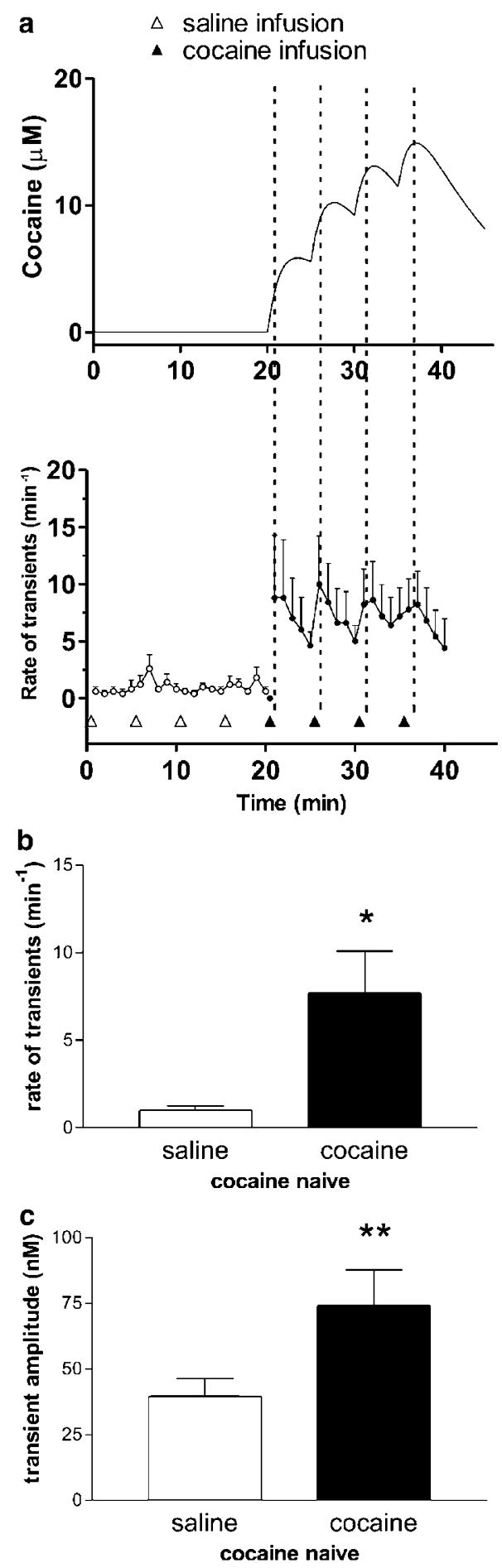

Figure 3 Noncontingent cocaine increases the frequency and amplitude of dopamine transients detected in naïve animals. (a) Upper: local cocaine concentration in the brain as calculated from equation (3) in Pan et al, 199|. Lower: mean rate of dopamine transients with SEM ( $n=5$ animals) following four noncontingent infusions of saline followed by four infusions of cocaine $(0.33 \mathrm{mg} / \mathrm{inf})$. The arrowheads indicate the infusion time. (b) Frequency of transients before and after noncontingent cocaine in cocainenaive animals. (c) Amplitude of transients before and after noncontingent cocaine in cocaine-naïve animals. $* \leqslant \leqslant 0.05, * * p \leqslant 0.0$ I vs saline.

was $1.0 \pm 0.3 \mathrm{~min}^{-1}$ and this increased almost eight-fold following noncontingent cocaine (frequency of dopamine transients after cocaine was $7.7 \pm 2.4 \mathrm{~min}^{-1}$, Figure $3 \mathrm{~b}$;
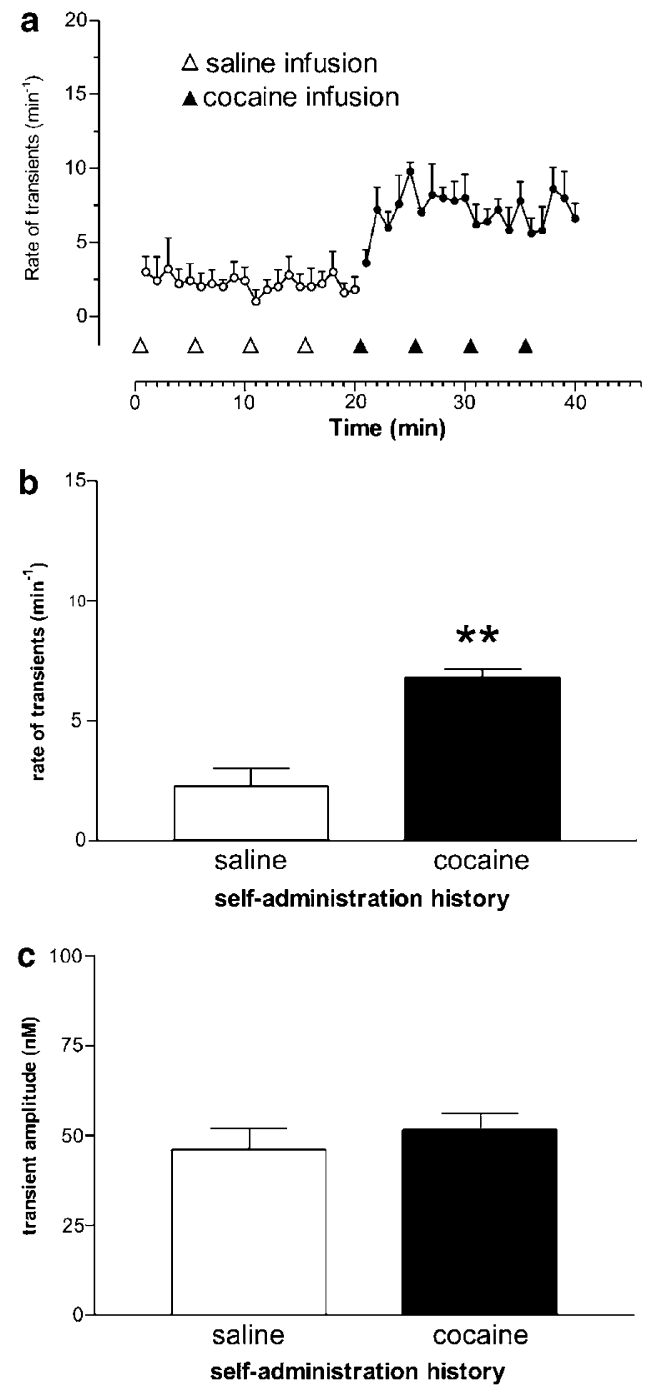

Figure 4 Noncontingent cocaine increases the frequency of dopamine transients detected in animals with a history of self-administration. (a) Mean rate of dopamine transients with SEM ( $n=5$ animals) following four noncontingent infusions of saline, followed by four infusions of cocaine $(0.33 \mathrm{mg} / \mathrm{inf})$. The arrowheads indicate the infusion time. (b) Frequency of transients before and after noncontingent cocaine in cocaine-experienced animals. (c) Amplitude of dopamine transients before and after noncontingent cocaine in cocaine-experienced animals. $* * * 0.00 \mathrm{I}$ vs saline.

$t(4)=2.94 ; p \leqslant 0.05)$. The mean amplitude of dopamine transients also significantly increased from $39.5 \pm 6.9 \mathrm{nM}$ during saline infusions to $74.1 \pm 13.6 \mathrm{nM}$ during cocaine infusions $(t(4)=4.49 ; p \leqslant 0.01$; Figure $3 c)$.

Similar results were obtained in animals with a history of cocaine self-administration (Figure 4a). In animals that had trained for 2 weeks to self-administer cocaine, the frequency of dopamine transients during saline infusions was $2.3 \pm 0.72 \mathrm{~min}^{-1}$ and it increased to $6.8 \pm 0.34 \mathrm{~min}^{-1}$ following noncontingent cocaine infusion (Figure $4 \mathrm{~b} ; t(4)=9.3$; $p \leqslant 0.001)$. When the frequency of dopamine transients from these two groups was compared, there was no significant main effect of cocaine history (cocaine experienced $v s$ cocaine naïve; $p>0.05)$ or an interaction $(p>0.05)$. However, during the cocaine infusion period in cocaineexperienced animals, dopamine transients did not signifi- 
a

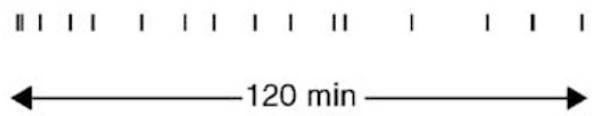

C

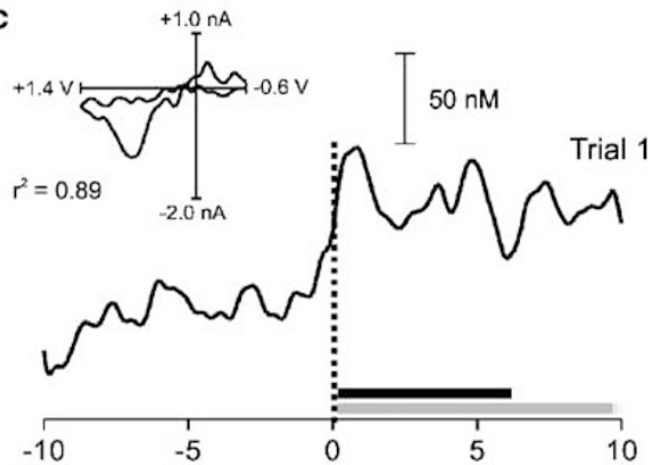

1.4.

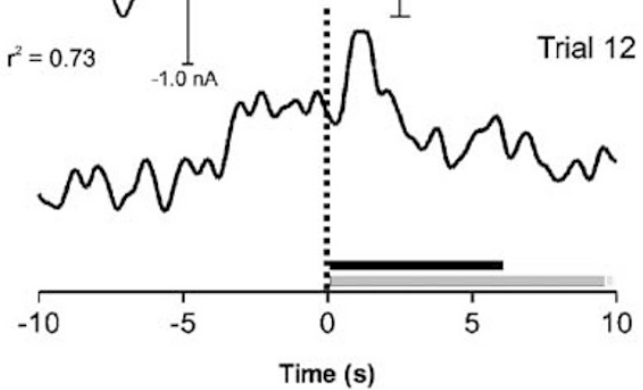

b
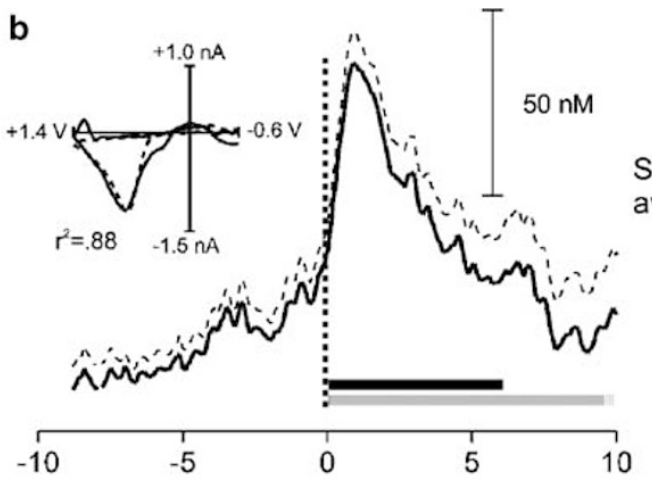

Session

average

Trial 11
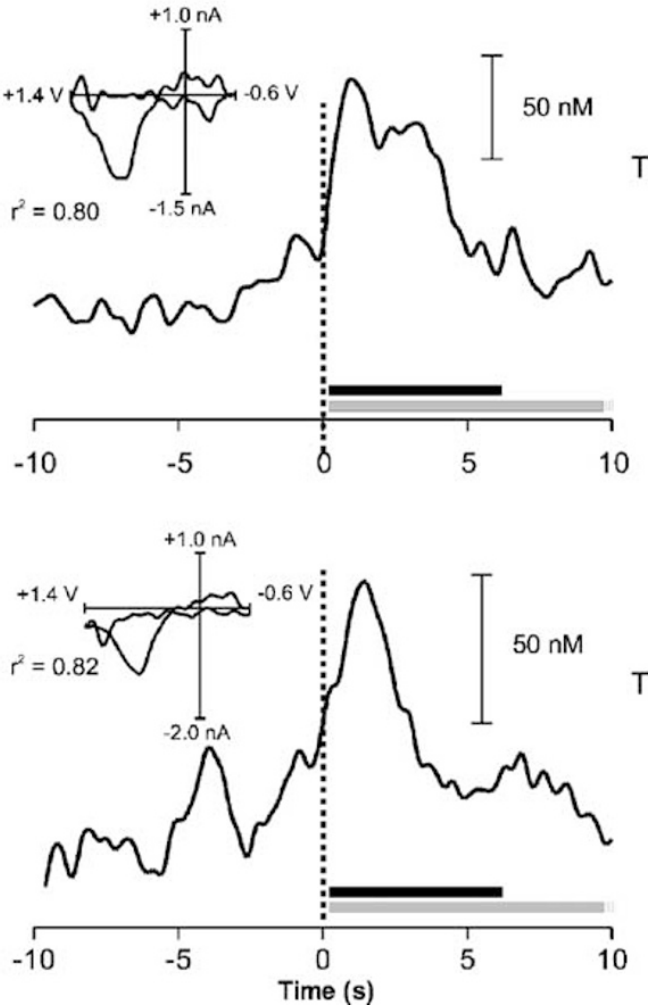

Trial 13

Figure 5 Examples of rapid dopaminergic signaling during cocaine self-administration. (a) A lever-press response record from a single animal during a 2-h self-administration session. Each vertical tick represents a single lever press for cocaine. (b) Average dopamine concentration change at $\pm 10 \mathrm{~s}$ around the lever press for cocaine (solid line) and SEM (dashed line) from each of the 16 presses in this rat. $t=0$ indicates the lever press, the black bar represents the duration of the infusion, and the gray bar represents the duration of drug-associated cues (which extend for an additional I0s). The average cyclic voltammogram (solid line, inset) shows a high correlation $\left(r^{2}=0.88\right)$ with that recorded during stimulated dopamine release (dashed line, inset). (c) Individual examples of phasic dopamine time-locked to the operant response to cocaine for specific trials from an individual rat showing the variability in responses. In all four panels, the cyclic voltammograms shown were recorded after the lever press and show a high correlation with that for dopamine ${ }^{2}{ }^{2}$ values when compared to stimulated dopamine release ranged between 0.73 and 0.89 ). Correlation coefficients for the events before the lever press were in the same range, but the dopamine transients occur at variable times relative to the lever press.

cantly increase in amplitude $(46.1 \pm 6.0 \mathrm{nM}$ during saline administration and $51.6 \pm 4.6 \mathrm{nM}$ during cocaine infusion; $p>0.05$, Figure $4 \mathrm{c})$. Thus, cocaine increased the frequency of dopamine transients in both naïve and cocaineexperienced animals, but the increase in transient amplitude was only seen in naïve animals.

\section{Dopamine Transients during Self-Administration of Cocaine}

During self-administration sessions, rats exhibited stable self-administration behavior as seen in the behavioral response pattern for a representative animal (Figure 5a). Dopamine transients were observed throughout the 2-h selfadministration session, with a mean frequency of $5.8 \pm 1.1 \mathrm{~min}^{-1}$. This frequency is not significantly different $(p>0.05)$ from that observed following noncontingent cocaine in rats with a self-administration history. Most transients occurred at random times and were not correlated with any specific behavior. However, as we have shown previously, dopamine transients were always seen around the lever press (Phillips et al, 2003b). The averaged result from all bar presses in this animal shows dopamine transients in the time interval $( \pm 10 \mathrm{~s})$ around the lever 
Table I Distribution of Dopamine Transients Relative to the Lever Presses $( \pm 10$ s) in Rats Trained to Press a Lever for Cocaine

\begin{tabular}{lccc}
\hline Rat \# & $\begin{array}{c}\text { \# of lever } \\
\text { presses }\end{array}$ & $\begin{array}{c}\text { \# of dopamine } \\
\text { transients } \\
\text { preceding lever } \\
\text { presses }\end{array}$ & $\begin{array}{c}\text { \# of dopamine } \\
\text { transients } \\
\text { following lever } \\
\text { presses }\end{array}$ \\
\hline 1 & 21 & 24 & 37 \\
2 & 16 & 13 & 21 \\
3 & 14 & 8 & 30 \\
4 & 17 & 15 & 22 \\
5 & 19 & 13 & 31 \\
6 & 23 & 18 & 35 \\
7 & 20 & 14 & 23 \\
8 & 21 & 17 & 22 \\
Average & 19 & 15.3 & 27.6 \\
\hline
\end{tabular}

press (Figure 5b). Dopamine began to rise $0.8 \mathrm{~s}$ before the lever press, reached a peak concentration of $69 \pm 12 \mathrm{nM}$ at $1.5 \mathrm{~s}$ after the lever press, and returned to baseline at $6.5 \mathrm{~s}$ after the press. The peak concentration is not significantly different $(p>0.05)$ from that for the random transients following cocaine in rats with a cocaine self-administration history. The averaged cyclic voltammogram (Figure 5, upper right inset) confirmed dopamine as the contributing species $\left(r^{2}=0.88\right)$.

Aspects of individual trials (Figure 5, lower four panels) are masked in the average. The dopamine transients before the lever press vary in their timing relative to the lever press, which causes them to be washed out in the average. The dopamine transients following the lever press are more time-locked and thus are not diluted in the average. The dopamine transients associated with the lever press for cocaine $( \pm 10 \mathrm{~s}$ around the press) are summarized in Table 1. A total of 343 dopamine transients were observed during 152 lever presses in eight animals. Of these, 122 $(36 \%)$ occurred in the $10 \mathrm{~s}$ before the lever press, while 221 (64\%) were observed within $10 \mathrm{~s}$ after the lever press. There are more transients than lever presses because, in some cases, two or three dopamine transients in close proximity followed the lever press. Among the dopamine transients before the lever press, 59 (42\%) occurred within $3 \mathrm{~s}$ before the operant response. Of the 221 dopamine transients observed post lever press, 115 (52\%) reached a maximum within $3 \mathrm{~s}$ after the response. Thus, in the $\pm 3 \mathrm{~s}$ around the lever press, the frequency of dopamine transients exceeds $11 \mathrm{~min}^{-1}$, almost double the rate observed during the remainder of the self-administration session.

\section{DISCUSSION}

The primary pharmacological effect of cocaine on dopamine-containing neurons is inhibition of uptake (Giros et al, 1996). In this study, uptake inhibition is observed by the decreased rate of dopamine clearance following its stimulated release. In addition, the subsecond measurements reveal an additional consequence of cocaine - the transient changes in extracellular dopamine in the nucleus accum- bens that normally occur in awake rats are increased in amplitude and frequency following its administration. The increase in frequency of dopamine release transients is a pharmacological effect, as demonstrated by its induction following noncontingent cocaine on a timescale that is similar to that for cocaine transport to the brain (Pan et al, 1991). During lever pressing for cocaine, similar dopamine transients occur, but the subset is closely time-locked to the lever press. These are evident before cocaine reaches the brain and exerts its pharmacological effect. Previously, we demonstrated that these dopamine transients are due to the learned association between cocaine, the operant response, and the environmental cues that predict drug delivery (Phillips et al, 2003b).

Fast-scan cyclic voltammetry provides high temporal resolution of the chemical dynamics of dopaminergic neurotransmission and allowed the first observation of naturally occurring, transient, release events (Robinson et al, 2002). While in vivo electrochemical techniques vary in their chemical selectivity (Di Chiara, 2002; Wightman and Robinson, 2002), fast-scan cyclic voltammetry has the best chemical resolution because the cyclic voltammograms for most electroactive species are distinct (Heien et al, 2003). As illustrated in Figure 1, both high temporal resolution and considerable chemical selectivity are required because dopamine changes are rapid and ionic changes, resembling changes in extracellular $\mathrm{pH}$, accompany and overlap both evoked and spontaneous dopamine transients. Other electrochemical studies of cocaine self-administration had insufficient time resolution to observe these changes (Gratton and Wise, 1994; Kiyatkin and Stein, 1995). Furthermore, they did not resolve the simultaneous chemical changes, and thus, their signals are likely a composite of several substances (eg including $\mathrm{pH}$ ). In this work, the chemical selectivity was higher; nonetheless, some transient dopamine changes may be beneath the threshold $(18 \mathrm{nM})$, set by the electrical noise of the system.

The rapid measurements of dopamine concentrations reveal the pharmacological effects of cocaine on dopamine neurons in two ways. First, stimulated dopamine release obtained after cocaine self-administration sessions show prolonged dopamine clearance (Figure $2 \mathrm{a}$ and $\mathrm{b}$ ), consistent with results following cocaine administration either in vitro (Jones et al, 1995) or in vivo (Wu et al, 2001). Uptake inhibition increases the lifetime of dopamine in the extracellular space, allowing diffusion over greater distances and the opportunity to interact with remote receptors (Venton et al, 2003a), and leads to a rise in dopamine concentration when sampled on a minute timescale with microdialysis (Wise et al, 1995). Second, dopamine transients increase in frequency following noncontingent cocaine (Figures $2 c$, d and 3 ). This occurred both in drugnaïve animals and those with a history of cocaine selfadministration, and the frequency following cocaine is similar to that in the nucleus accumbens of rats leverpressing for cocaine. The cocaine-induced transients in the drug-naïve rats were larger than in the two other groups. This suggests that both contingent and noncontingent cocaine cause an adaptation in the mechanism(s) responsible for these transients. As noncontingent administration of nomifensine, another dopamine uptake inhibitor, also causes these effects (Robinson and Wightman, 2004), they 
appear to be a general consequence of dopamine uptake inhibition. The increase in amplitude of the spontaneous, transient dopamine release events is quite similar to the increase in electrically stimulated release that is seen after uptake inhibition (Wu et al, 2001).

The naturally occurring, spontaneous, dopamine transients occur at relatively low frequency, are not associated with specific external cues or behavioral responses, and their function is currently unknown. However, their amplitude is sufficient to activate high-affinity dopaminergic receptors located on post-synaptic cells in the nucleus accumbens (Richfield et al, 1989). Electrophysiological studies in behaving rats (Hyland et al, 2002) have demonstrated that dopamine-containing neurons burst fire on a timescale similar to the observed dopamine transients. Burst firing, in turn, is driven by excitatory glutamatergic and cholinergic inputs to dopamine-containing cells (Kitai et al, 1999; Floresco et al, 2003; Paladini et al, 2004). Dopamine release evoked with parameters that mimic a dopaminergic burst (Figure 1a) has a similar time course as the naturally occurring signals. Another pharmacological challenge that causes dopamine release transients is CB1 cannabinoid receptor activation (Cheer et al, 2004), a process that causes increased burst firing of dopamine-containing neurons (Gessa et al, 1998).

Both noncontingent and self-administered cocaine cause these naturally occurring release events to increase in frequency. The mechanism responsible for this is unclear, since cocaine partially inhibits VTA dopaminergic cell firing both in brain slices (Bunney et al, 2000) and in anesthetized rats (Einhorn et al, 1988). Cocaine and other pyschostimulants can induce low-frequency oscillations in the firing rate of dopamine-containing neurons; however, this has only been demonstrated in anesthetized rats following dopamine receptor blockade with raclopride (Shi et al, 2004). Alternatively, local activation in the nucleus accumbens by excitatory afferents may evoke these transients (Parkinson et al, 2000).

Despite the presence of ongoing dopamine release events following cocaine self-administration, there is a subset of dopamine transient release events that are tightly linked to the animal behavior at the time of the lever press (Figures 1 and 5), a time removed by several minutes from that of the maximal brain cocaine levels. In particular, the transients immediately following the lever press, occasionally exhibiting multiple peaks, always occur within a few seconds of the press. In contrast, the pharmacologically induced dopamine transients during noncontingent cocaine administration are absent in this time interval (compare Figures $2 \mathrm{f}$ and 5). Our previous results implicate that transients can code reward expectation because they occur in response to drug-predictive cues in the absence of cocaine (Phillips et al, 2003b). Thus, dopamine transients associated with reward are consistent with the increased burst firing of VTA neurons in primates during rewardrelated events (Waelti et al, 2001). Increases in dopamine in response to cocaine-associated cues can also be observed by microdialysis (Ito et al, 2000; Weiss et al, 2000), but more complex experimental designs must be used to separate temporally the contingent from the pharmacological effects. The dopamine transients immediately preced- ing the lever press are more variable in their occurrence (Table 1) and are not so tightly time-locked to it, but are more closely correlated with the initiation of appetitive behaviors. We have noted previously that dopamine transients preceding the lever press occur when the animal initiates the approach to the lever. As there is a high degree of variability in the time between when the animal approaches the lever, and when they actually press it, this may explain why the pre-response transients are variable. Indeed, evoking dopamine release on this timescale promotes drug seeking (Phillips et al, 2003b). Consistently, similar dopamine transients are seen in trained rats at the onset of a cue that promotes lever pressing for sucrose (Roitman et al, 2004).

Previous studies have implicated an important role of dopamine in both the reinforcing (Wise et al, 1995) and conditioned effects (Ito et al, 2000; Weiss et al, 2000) of cocaine. In those studies, dopamine was measured on a relatively long timescale (over minutes) using microdialysis. The rapid dopamine signaling reported here results from both pharmacological and conditioned effects of cocaine. Although dopamine alone is not responsible for the manifestation of specific behaviors, it can modulate neural signals underlying behavior (Carelli, 2004). Here we have revealed a new temporal domain of dopaminergic chemical transmission that is relevant to behavior and is highly susceptible to modification by psychoactive drugs and associated conditioning effects.

\section{ACKNOWLEDGEMENTS}

The authors thank MLAV Heien, SE Brooks, JH Wondolowski, and the UNC Electronics Facility. This work was supported by grants from the National Institute on Drug Abuse; DA10900 (RMW), DA17318 (RMC \& RMW), and DA015923 (GDS).

\section{REFERENCES}

Baldo BA, Daniel RA, Berridge CW, Kelley AE (2003). Overlapping distributions of orexin/hypocretin- and dopamine-beta-hydroxylase immunoreactive fibers in rat brain regions mediating arousal, motivation, and stress. J Comp Neurol 464: 220-237.

Bradberry CW (2000). Acute and chronic dopamine dynamics in a nonhuman primate model of recreational cocaine use. J Neurosci 20: 7109-7115.

Bunney EB, Appel SB, Brodie MS (2000). Cocaine potentiates ethanol-induced excitation of dopaminergic reward neurons in the ventral tegmental area. J Pharmacol Exp Ther 293: 383-389.

Caine SB, Koob GF (1994). Effects of dopamine D-1 and D-2 antagonists on cocaine self-administration under different schedules of reinforcement in the rat. J Pharmacol Exp Ther 270: 209-218.

Carelli RM (2004). Nucleus accumbens cell firing and rapid dopamine signaling during goal-directed behaviors in rats. Neuropharmacology 47(Suppl 1): 180-189.

Carelli RM, Deadwyler SA (1996). Dose-dependent transitions in nucleus accumbens cell firing and behavioral responding during cocaine self-administration sessions in rats. J Pharmacol Exp Ther 277: 385-393.

Carelli RM, Ijames SG, Crumling AJ (2000). Evidence that separate neural circuits in the nucleus accumbens encode cocaine versus 'natural' (water and food) reward. J Neurosci 20: 4255-4266. 
Chang JY, Sawyer SF, Lee RS, Woodward DJ (1994). Electrophysiological and pharmacological evidence for the role of the nucleus accumbens in cocaine self-administration in freely moving rats. J Neurosci 14: 1224-1244.

Cheer JF, Wassum KM, Heien ML, Phillips PE, Wightman RM (2004). Cannabinoids enhance subsecond dopamine release in the nucleus accumbens of awake rats. J Neurosci 24: 4393-4400.

Ciccocioppo R, Martin-Fardon R, Weiss F (2004). Stimuli associated with a single cocaine experience elicit long-lasting cocaine-seeking. Nat Neurosci 7: 495-496.

Dackis CA, O'Brien CP (2001). Cocaine dependence: a disease of the brain's reward centers. J Subst Abuse Treat 21: 111-117.

Di Chiara G (2002). Nucleus accumbens shell and core dopamine: differential role in behavior and addiction. Behav Brain Res 137: 75-114.

Di Chiara G, Bassareo V, Fenu S, De Luca MA, Spina L, Cadoni C et al (2004). Dopamine and drug addiction: the nucleus accumbens shell connection. Neuropharmacology 47(Suppl 1): 227-241.

Di Chiara G, Imperato A (1988). Drugs abused by humans preferentially increase synaptic dopamine concentrations in the mesolimbic system of freely moving rats. Proc Natl Acad Sci USA 85: $5274-5278$.

Einhorn LC, Johansen PA, White FJ (1988). Electrophysiological effects of cocaine in the mesoaccumbens dopamine system: studies in the ventral tegmental area. J Neurosci 8: 100-112.

Everitt BJ, Robbins TW (2000). Second-order schedules of drug reinforcement in rats and monkeys: measurement of reinforcing efficacy and drug-seeking behaviour. Psychopharmacology (Berl) 153: $17-30$.

Floresco SB, West AR, Ash B, Moore H, Grace AA (2003). Afferent modulation of dopamine neuron firing differentially regulates tonic and phasic dopamine transmission. Nat Neurosci 6: 968-973.

Garris PA, Christensen JR, Rebec GV, Wightman RM (1997). Realtime measurement of electrically evoked extracellular dopamine in the striatum of freely moving rats. J Neurochem 68: 152-161.

Garris PA, Collins LB, Jones SR, Wightman RM (1993). Evoked extracellular dopamine in vivo in the medial prefrontal cortex. J Neurochem 61: 637-647.

Gawin FH (1991). Cocaine addiction: psychology and neurophysiology. Science 251: 1580-1586.

Gessa GL, Melis M, Muntoni AL, Diana M (1998). Cannabinoids activate mesolimbic dopamine neurons by an action on cannabinoid CB1 receptors. Eur J Pharmacol 341: 39-44.

Giros B, Jaber M, Jones SR, Wightman RM, Caron MG (1996). Hyperlocomotion and indifference to cocaine and amphetamine in mice lacking the dopamine transporter. Nature 379: 606-612.

Gratton A, Wise RA (1994). Drug- and behavior-associated changes in dopamine-related electrochemical signals during intravenous cocaine self-administration in rats. J Neurosci 14: 4130-4146.

Heien ML, Phillips PE, Stuber GD, Seipel AT, Wightman RM (2003). Overoxidation of carbon-fiber microelectrodes enhances dopamine adsorption and increases sensitivity. Analyst 128: 1413-1419.

Hyland BI, Reynolds JN, Hay J, Perk CG, Miller R (2002). Firing modes of midbrain dopamine cells in the freely moving rat. Neuroscience 114: 475-492.

Ito R, Dalley JW, Howes SR, Robbins TW, Everitt BJ (2000). Dissociation in conditioned dopamine release in the nucleus accumbens core and shell in response to cocaine cues and during cocaine-seeking behavior in rats. J Neurosci 20: 7489-7495.

Johnson LR, Aylward RL, Hussain Z, Totterdell S (1994). Input from the amygdala to the rat nucleus accumbens: its relationship with tyrosine hydroxylase immunoreactivity and identified neurons. Neuroscience 61: 851-865.
Jones SR, Garris PA, Wightman RM (1995). Different effects of cocaine and nomifensine on dopamine uptake in the CaudatePutamen and nucleus accumbens. J Pharmacol Exp Ther 274: 396-403.

Kitai ST, Shepard PD, Callaway JC, Scroggs R (1999). Afferent modulation of dopamine neuron firing patterns. Curr Opin Neurobiol 9: 690-697.

Kiyatkin EA, Stein EA (1995). Fluctuations in nucleus accumbens dopamine during cocaine self-administration behavior: an in vivo electrochemical study. Neuroscience 64: 599-617.

Koob GF, Ahmed SH, Boutrel B, Chen SA, Kenny PJ, Markou A et al (2004). Neurobiological mechanisms in the transition from drug use to drug dependence. Neurosci Biobehav Rev 27: 739-749.

Kuhr WG, Bigelow JC, Wightman RM (1986). In vivo comparison of the regulation of releasable dopamine in the caudate nucleus and the nucleus accumbens of the rat brain. J Neurosci 6: 974-982.

Nicola SM, Surmeier J, Malenka RC (2000). Dopaminergic modulation of neuronal excitability in the striatum and nucleus accumbens. Annu Rev Neurosci 23: 185-215.

O'Brien CP, Childress AR, McLellan AT, Ehrman R (1992). Classical conditioning in drug-dependent humans. Ann NY Acad Sci 654: 400-415.

O'Donnell P, Greene J, Pabello N, Lewis BL, Grace AA (1999). Modulation of cell firing in the nucleus accumbens. Ann NY Acad Sci 877: 157-175.

Paladini CA, Mitchell JM, Williams JT, Mark GP (2004). Cocaine self-administration selectively decreases noradrenergic regulation of metabotropic glutamate receptor-mediated inhibition in dopamine neurons. J Neurosci 24: 5209-5215.

Pan HT, Menacherry S, Justice Jr JB (1991). Differences in the pharmacokinetics of cocaine in naive and cocaine-experienced rats. J Neurochem 56: 1299-1306.

Parkinson JA, Cardinal RN, Everitt BJ (2000). Limbic corticalventral striatal systems underlying appetitive conditioning. Prog Brain Res 126: 263-285.

Paxinos G, Watson C (1997). The Rat Brain in Stereotaxic Coordinates. Academic Press: San Diego.

Pennartz CM, Groenewegen HJ, Lopes da Silva FH (1994). The nucleus accumbens as a complex of functionally distinct neuronal ensembles: an integration of behavioural, electrophysiological and anatomical data. Prog Neurobiol 42: 719-761.

Pettit HO, Justice Jr JB (1989). Dopamine in the nucleus accumbens during cocaine self-administration as studied by in vivo microdialysis. Pharmacol Biochem Behav 34: 899-904.

Pettit HO, Justice Jr JB (1991). Effect of dose on cocaine selfadministration behavior and dopamine levels in the nucleus accumbens. Brain Res 18: 94-102.

Phillips PE, Robinson DL, Stuber GD, Carelli RM, Wightman RM (2003a). Real-time measurements of phasic changes in extracellular dopamine concentration in freely moving rats by fastscan cyclic voltammetry. Methods Mol Med 79: 443-464.

Phillips PE, Stuber GD, Heien ML, Wightman RM, Carelli RM (2003b). Subsecond dopamine release promotes cocaine seeking. Nature 422: 614-618.

Phillips PE, Wightman RM (2003). Critical guidelines for validation of the selectivity of in-vivo chemical microsensors. Trends Anal Chem 22: 509-514.

Rebec GV, Christensen JR, Guerra C, Bardo MT (1997). Regional and temporal differences in real-time dopamine efflux in the nucleus accumbens during free-choice novelty. Brain Res 776: 61-67.

Richfield EK, Penney JB, Young AB (1989). Anatomical and affinity state comparisons between dopamine $D_{1}$ and $D_{2}$ receptors in the rat central nervous system. Neuroscience 30: 767-777.

Robinson DL, Heien ML, Wightman RM (2002). Frequency of dopamine concentration transients increases in dorsal and 
ventral striatum of male rats during introduction of conspecifics. J Neurosci 22: 10477-10486.

Robinson DL, Wightman RM (2004). Nomifensine amplifies subsecond dopamine signals in the ventral striatum of freelymoving rats. J Neurochem 90: 894-903.

Roitman MF, Stuber GD, Phillips PE, Wightman RM, Carelli RM (2004). Dopamine operates as a subsecond modulator of food seeking. J Neurosci 24: 1265-1271.

Salamone JD, Correa M (2002). Motivational views of reinforcement: implications for understanding the behavioral functions of nucleus accumbens dopamine. Behav Brain Res 137: 3-25.

Schultz W (1998). Predictive reward signal of dopamine neurons. J Neurophysiol 80: 1-27.

See RE, Fuchs RA, Ledford CC, McLaughlin J (2003). Drug addiction, relapse, and the amygdala. Ann NY Acad Sci 985: 294-307.

Sesack SR, Pickel VM (1990). In the rat medial nucleus accumbens, hippocampal and catecholaminergic terminals converge on spiny neurons and are in apposition to each other. Brain Res 527: 266-279.

Shi WX, Pun CL, Zhou Y (2004). Psychostimulants induce lowfrequency oscillations in the firing activity of dopamine neurons. Neuropsychopharmacology 29: 2160-2167.

Stewart J (1992). Neurobiology of conditioning to drugs of abuse. Ann NY Acad Sci 654: 335-346.

Totterdell S, Smith AD (1989). Convergence of hippocampal and dopaminergic input onto identified neurons in the nucleus accumbens of the rat. J Chem Neuroanat 2: 285-298.

Uzwiak AJ, Guyette FX, West MO, Peoples LL (1997). Neurons in accumbens subterritories of the rat: phasic firing time-locked within seconds of intravenous cocaine self-infusion. Brain Res 767: 363-369.

Venton BJ, Michael DJ, Wightman RM (2003b). Correlation of local changes in extracellular oxygen and $\mathrm{pH}$ that accompany dopaminergic terminal activity in the rat caudate-putamen. $J$ Neurochem 84: 373-381.

Venton BJ, Zhang H, Garris PA, Phillips PE, Sulzer D, Wightman RM (2003a). Real-time decoding of dopamine concentration changes in the caudate-putamen during tonic and phasic firing. $J$ Neurochem 87: 1284-1295.

Volkow ND, Fowler JS, Wang GJ (2003). The addicted human brain: insights from imaging studies. J Clin Invest 111: 1444-1451.

Waelti P, Dickinson A, Schultz W (2001). Dopamine responses comply with basic assumptions of formal learning theory. Nature 412: 43-48.

Weiss F, Maldonado-Vlaar CS, Parsons LH, Kerr TM, Smith DL, Ben Shahar O (2000). Control of cocaine-seeking behavior by drug-associated stimuli in rats: effects on recovery of extinguished operant-responding and extracellular dopamine levels in amygdala and nucleus accumbens. Proc Natl Acad Sci USA 97: 4321-4326.

Wightman RM, Robinson DL (2002). Transient changes in mesolimbic dopamine and their association with 'reward'. J Neurochem 82: 721-735.

Wise RA (1982). Common neural basis for brain stimulation reward, drug reward, and food reward. In BG Hoebel, D Novin (eds). The Neural Basis of Feeding and Reward. Haer Institute: Brunswick, ME. pp 445-454.

Wise RA (2004). Dopamine, learning and motivation. Nat Rev Neurosci 5: 483-494.

Wise RA, Newton P, Leeb K, Burnette B, Pocock D, Justice Jr JB (1995). Fluctuations in nucleus accumbens dopamine concentration during intravenous cocaine self-administration in rats. Psychopharmacology (Berl) 120: 10-20.

Wu Q, Reith ME, Kuhar MJ, Carroll FI, Garris PA (2001). Preferential increases in nucleus accumbens dopamine after systemic cocaine administration are caused by unique characteristics of dopamine neurotransmission. J Neurosci 21: 6338-6347. 